\title{
Torque Model in Plate Rolling Process with Biting Impact Considered
}

\author{
Zhijie JIAO, ${ }^{1) *}$ Chunyu HE, ${ }^{1)}$ Longxin WANG, ${ }^{1)}$ Yuanliang CAI, ${ }^{1)}$ Xu WANG ${ }^{1)}$ and Xudong SUN ${ }^{2)}$ \\ 1) The State Key Laboratory of Rolling and Automation, Northeastern University, Shenyang Liaoning, 110819 China. \\ 2) The Heavy Plate Plant, NISCO, Nanjing Jiangshu, 210035 China.
}

(Received on April 21, 2020; accepted on July 10, 2020; J-STAGE Advance published date: September $5,2020)$

\begin{abstract}
In this paper, the research work of the torque model in plate rolling process, with biting impact considered, is carried out based on mechanical dynamics and the rolling process technology. The five-degree-offreedom mechanical dynamic model was established for the main drive system of the actual heavy plate mill, considering the clearance between parts. The biting peak torques under different rolling process conditions were calculated. The influence of the biting time and the steady-state torque were analyzed: the biting peak torque decreases with the biting time increasing, and increases with the steady-state torque increasing. The biting time calculation model was established based on the rolling process parameters. The steady-state torque model was improved by rebuilding level arm ratio model. The influence of deformation area arithmetic average aspect ratio and reduction rate was considered. The calculation model of biting peak torque is built with biting time and steady-state torque influence. The model accuracy is verified by comparing the calculated data with actual data. The average deviation of steady-state torque and peak biting impact torque is within $\pm 8 \%$, and $\pm 10 \%$. The accuracy of these models can be improved by offline intelligent method and online learning function, subsequently.
\end{abstract}

KEY WORDS: plate rolling; torque; biting impact; model.

\section{Introduction}

Due to the steel grades diversification and the dimensional accuracy requirements, the plate mill setup is required to be more flexible and accurate. Torque is one of the most important parameters in the plate rolling process. The precise torque model can help us to improve the control of the plate rolling process, optimize the pass schedule and take full advantage of mill equipment.

During one pass of plate rolling, torque changes seriously, especially at the head biting moment. Figure 1 shows the actual torque situation of one pass. There is a great impact during the head biting period, and then it gradually becomes stable. In addition to the rolling technology theory, the mechanical dynamics should also be considered in the head biting impact process. Therefore, in the study of torque model, not only the influence factors of rolling process, but also the biting impact should be considered.

Researchers have carried out various works on the torque model. Based on the rolling process theory, a series of assumptions are made on the rolling condition, the differ-

\footnotetext{
* Corresponding author: E-mail: jiaozj@ral.neu.edu.cn
}

ential equations of parameters in the deformation zone are established and solved to obtain the analytical model of rolling force and torque. ${ }^{1-7)}$ Base on this, the empirical torque model is given by considering the level arm ratio. ${ }^{8-10)}$ The rolling force and torque under different process conditions are also calculated through the finite element numerical analysis, and the regression torque model is established. ${ }^{11)}$ With the development of artificial intelligence technology, artificial neural network and other intelligent optimization methods are also applied to improve the accuracy of torque model. ${ }^{10-13)}$ The developments of rolling theory, including torque model, were reviewed by P. Montmitonnet, P. Buessler, and M. Ataka. ${ }^{14,15)}$

For the analysis of the biting impact stage, H. Jewik, R. P. Stratford, and C. W. Thomas proposed the concept of Torque Amplification Factor (TAF) to measure the degree of head impact. ${ }^{16)}$ From now on, the mathematical model of torsional vibration system was established based on mechanical dynamics. The influence of clearance size, clearance position, biting time, and other factors on the head impact were analyzed. ${ }^{17-22)}$ The impact load cause was also analyzed. ${ }^{23)}$ And, the methods for reducing the head biting impact were proposed. ${ }^{24-26)}$

These research works were carried out to study the torque 
model of the steady-state rolling process and the torque variation of the biting impact process. Nevertheless, the biting impact stage and the steady-state rolling process are closely related, and the stable rolling torque also affect the biting impact torque, directly.

The draft schedule and mill setup calculation for the plate rolling process are generally based on the stable torque. Based on this, the biting impact is considered through a safety factor. With the continuous expansion of plate varieties and specifications, the share of high-strength steel in products is increasing, and the requirement for equipment capabilities has become stricter. It is necessary to maximize equipment capabilities on the premise of ensuring equipment safety. However, the peak torque during the biting impact period is the critical limit condition. Therefore, the torque model with biting impact considered must be studied furtherly.

In the section 2 of this article, a five-degree-of-freedom mechanical dynamics model of the mill main drive system is established, based on the actual equipment data of a heavy plate mill. And the dynamic response of the mill drive system was simulated and analyzed using MATLAB software. In the section 3 , the influence of bite time and steady-state torque on head biting impact torque were studied. In the section 4 , the biting time calculation model was determined based on the rolling process parameters. The steady-state torque calculation model was established through regression of actual data. And then the biting impact torque model was regressed of simulation data, with biting time and steady rolling torque considered.

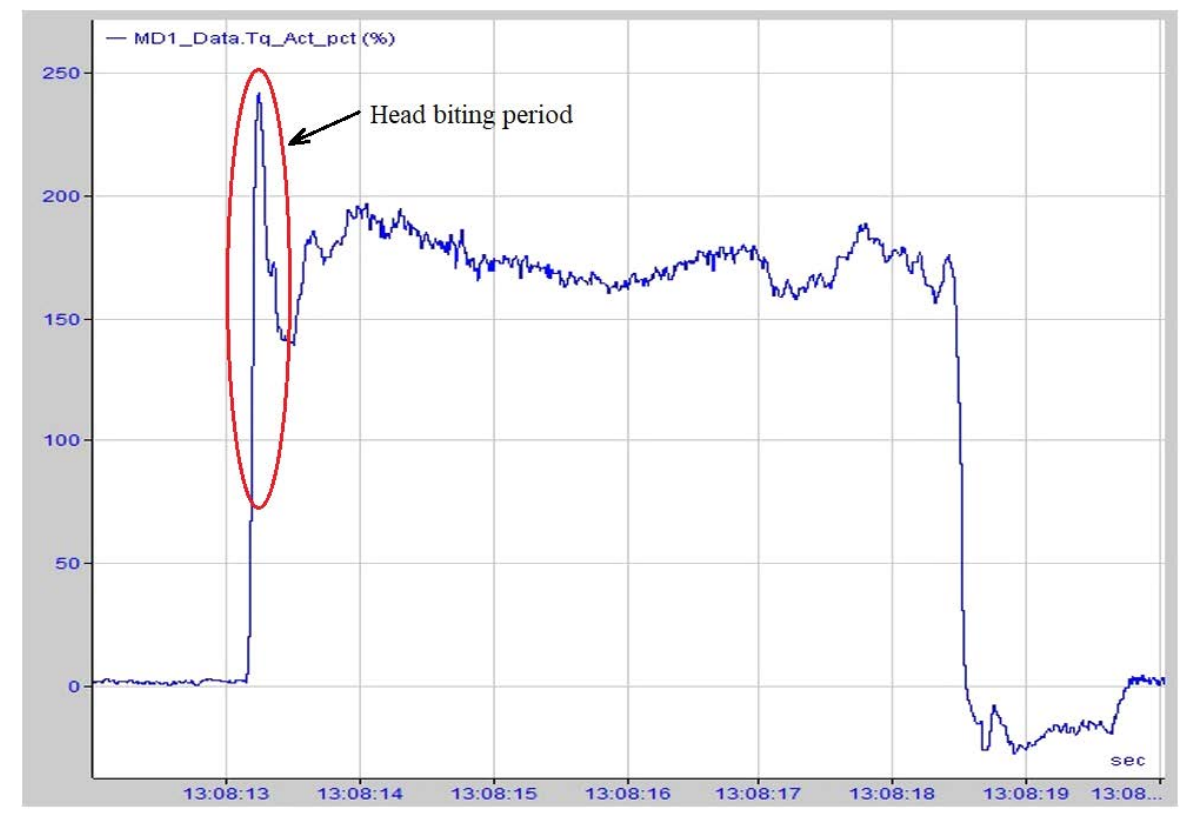

Fig. 1. Actual torque situation of one pass rolling process. (Online version in color.)
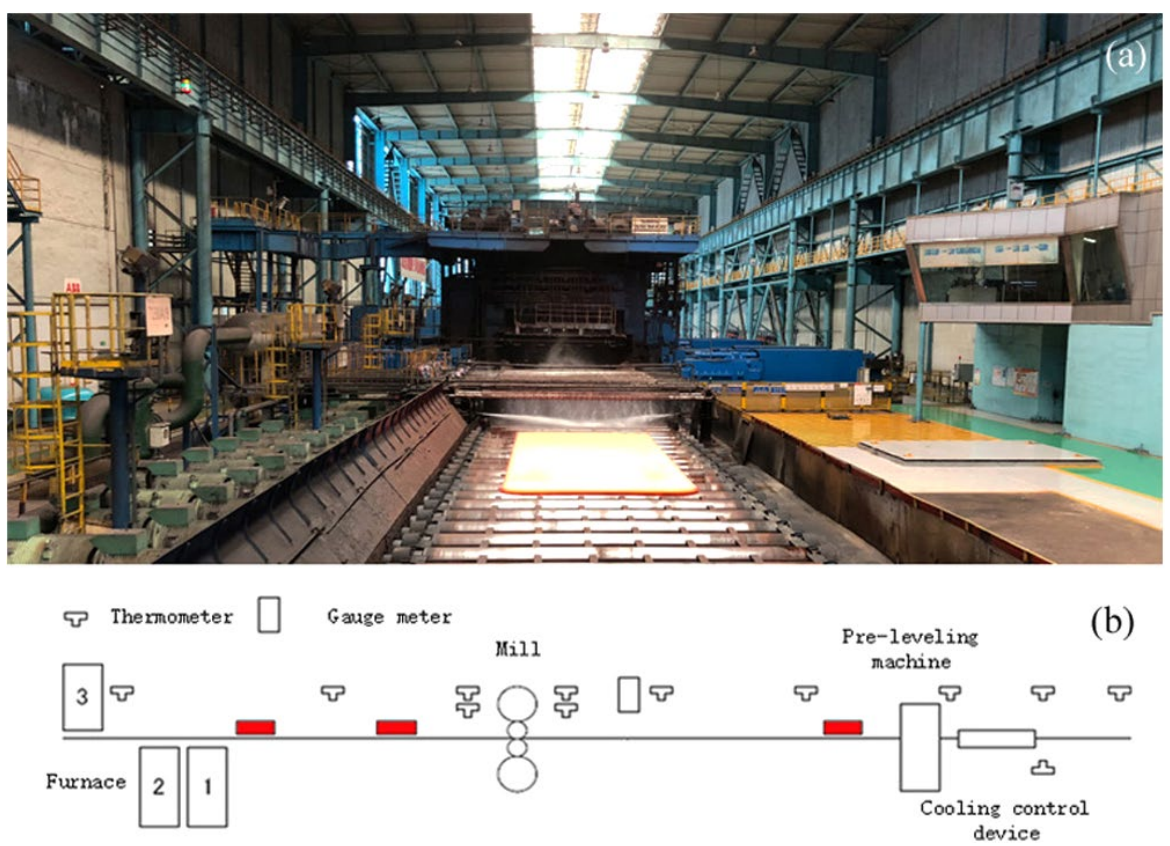

Fig. 2. Layout of the plate mill line: (a) plate mill; (b) equipment layout of plate mill line. (Online version in color.) 


\section{Main Drive System Model of Plate Mill and its Dynamic Response}

\subsection{Modeling of Mill Main Drive System}

2.1.1. Process Equipment in the Plate Mill Line

The primary equipment in a heavy plate factory production line is a single-stand four-high reversing mill. Other auxiliary equipment mainly includes furnace, pre-leveling machine, cooling control device, etc. The photo of the plate mill and the layout of the primary instruments and equipment of the plate mill line are shown in Fig. 2. The plate mill process parameters are listed in Table $\mathbf{1}$.

\subsubsection{Physical Model of Main Drive System}

The main drive system of the plate mill mainly includes rolls, flat heads, flat head covers, mill side universal joints,

Table 1. Process parameters of plate mill

\begin{tabular}{cc}
\hline Items & Parameters \\
\hline Work roll size & $\Phi 1110 / 1210 \times 5300 \mathrm{~mm}$ \\
Backup roll size & $\Phi 2100 / 2300 \times 4950 \mathrm{~mm}$ \\
Motor rated speed & $45 \mathrm{r} / \mathrm{min}$ \\
Motor max speed & $100 \mathrm{r} / \mathrm{min}$ \\
Max rolling force & $120000 \mathrm{kN}$ \\
Rated torque & $2 \times 2122 \mathrm{kN} \cdot \mathrm{m}$ \\
Motor power & $2 \times 10000 \mathrm{~kW}$ \\
\hline
\end{tabular}

motor side universal joints, flanges, and motor rotors. A schematic layout of the main drive system for the heavy plate mill is shown in Fig. 3. Three-dimensional solid modeling is performed on the main equipment of mill, such as the transmission device, the work roll and the backup roll, as shown in Fig. 4.

\subsubsection{Dynamics Model of the Main Drive System}

The main drive system is regarded as a mass-spring system composed with several inertial elements and elastic elements, and the dynamic model of the main drive system is established by the centralized mass method. ${ }^{17,18)}$ The upper and down rolls of the plate mill are driven by two motors respectively. According to the mechanical structure diagrams of the main drive system in Figs. 3 and 4, the upper and down drive systems are completely same, except the structure of the output shaft. Therefore, the upper and down main drive systems can be simplified to two independent five-degree-of-freedom straight-line models, as shown in Fig. 5. $J 1, J 2, J 3, J 4, J 5$ are the equivalent inertias of motor rotor, motor side flat head, support bearing joint, roll side flat head, and roll respectively. We call output shaft as segment 1 , segment between motor side flat head and support bearing as segment 2 , segment between support bearing section and roll side flat head section as segment 3 , segment between roll side flat head and roll as segment 4. $K 1, K 2$, $K 3, K 4$ are the equivalent torsional stiffness of segment 1 , segment 2, segment 3 and segment4 respectively. $C 1, C 2$, $C 3, C 4$ are the equivalent damping of segment 1 , segment

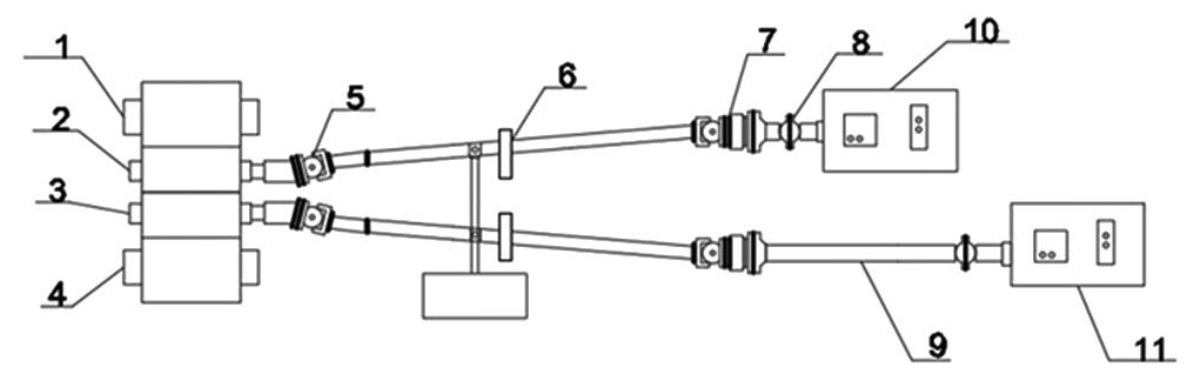

Fig. 3. Schematic layout of main drive system for plate mill:1-upper backup roll, 2-upper work roll, 3-down work roll, 4-down backup roll, 5-mill side universal joint shaft, 6-backup bearing section, 7-motor side flat head section, 8-flange, 9-output shaft, 10-upper motor, 11-down motor.

(a)

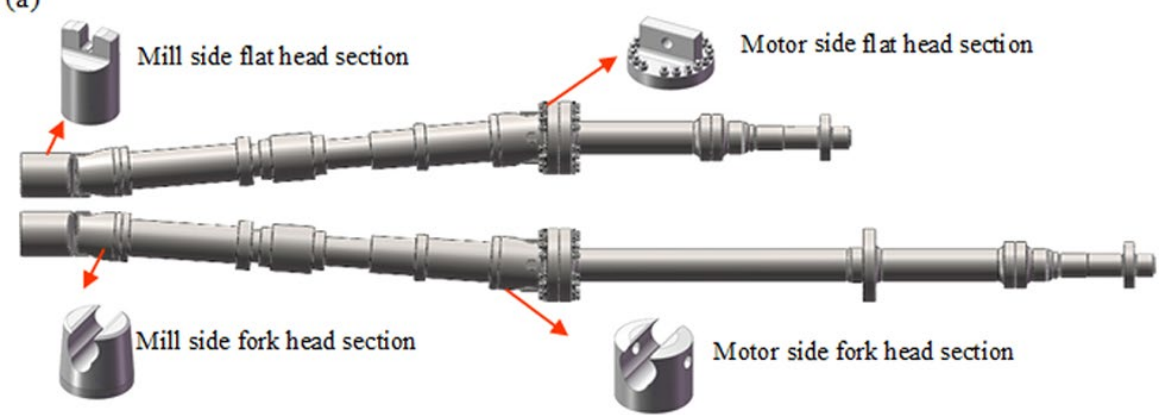

(b)

(c)
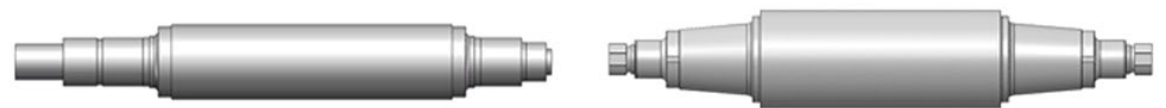

Fig. 4. Schematic of complex parts of main drive system: (a)Transmission device; (b) Work roll; (c) Backup roll. (Online version in color.) 


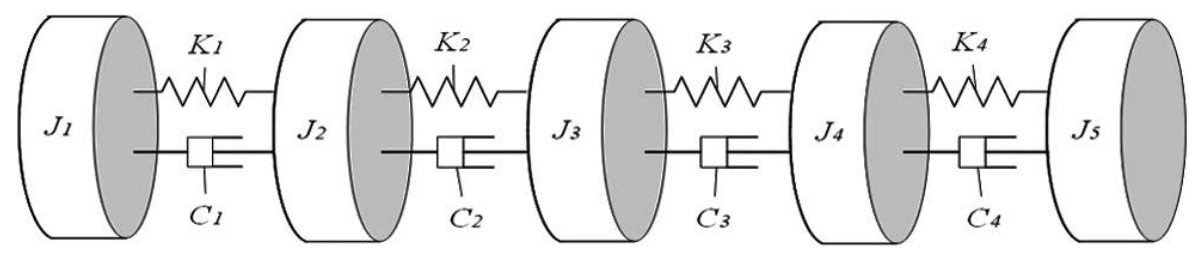

Fig. 5. Dynamic model of the main drive system.

2 , segment 3 and segment 4 respectively.

According to the load analysis of the mass-spring system, the differential equation of the main drive system can be obtained as follows:

$$
[J]\{\ddot{\theta}\}+[C]\{\dot{\theta}\}+[K]\{\theta\}=\left\{M_{F}\right\}
$$

Where, $[J]$ is inertia matrix as Eq. (2), $[C]$ is damping matrix as Eq. (3), $[K]$ is stiffness matrix as Eq. (4), $\{\theta\},\{\dot{\theta}\}$ and $\{\ddot{\theta}\}$ are angular displacement, angular velocity and angular acceleration of shaft segment respectively, and $\left\{M_{F}\right\}$ is external load of the system.

$$
\begin{gathered}
{[J]=\left[\begin{array}{ccccc}
J_{1} & 0 & 0 & 0 & 0 \\
0 & J_{2} & 0 & 0 & 0 \\
0 & 0 & J_{3} & 0 & 0 \\
0 & 0 & 0 & J_{4} & 0 \\
0 & 0 & 0 & 0 & J_{5}
\end{array}\right] \ldots \ldots \ldots \ldots \ldots(2)} \\
{[C]=\left[\begin{array}{ccccc}
C_{1} & -C_{1} & 0 & 0 & 0 \\
-C_{1} & C_{1}+C_{2} & -C_{2} & 0 & 0 \\
0 & -C_{2} & C_{2}+C_{3} & -C_{3} & 0 \\
0 & 0 & C_{3} & C_{3}+C_{4} & -C_{4} \\
0 & 0 & 0 & -C_{4} & C_{4}
\end{array}\right] \ldots(3)} \\
{[K]=\left[\begin{array}{ccccc}
K_{1} & -K_{1} & 0 & 0 & 0 \\
-K_{1} & K_{1}+K_{2} & -K_{2} & 0 & 0 \\
0 & -K_{2} & K_{2}+K_{3} & -K_{3} & 0 \\
0 & 0 & K_{3} & K_{3}+K_{4} & -K_{4} \\
0 & 0 & 0 & -K_{4} & K_{4}
\end{array}\right] \ldots(4)}
\end{gathered}
$$

\subsubsection{Influence of Clearance between Parts}

The main drive system has clearance between parts, due to the fitting error, wear and other factors. At the biting moment, the clearance will be opened and closed repeatedly, it makes the torsional vibration of the main drive system more severe, and a larger torque peak will appear. In this case, the stiffness and damping will also appear time-varying and nonlinear. ${ }^{19,20)}$ Assume that the system has a clearance size of $2 e$ at the segment 1 . If each oscillator of the system starts to move from a stationary state, the coordinate origin is the midpoint of the clearance, and the system starts to move from the middle of the clearance. When $\theta_{1}-\theta_{2}>e$, the oscillator 1 in the system has a right collision; when $-e<\theta_{1}-\theta_{2}<\mathrm{e}$, the clearance is now open; when $\theta_{1}-\theta_{2}<-\mathrm{e}$, the oscillator 1 in the system has a left collision. So, the damping matrix and stiffness matrix expressions of segment 1 are modified as following Eqs. (5) and (7). The expression is similar in other shaft segments, if the clearance exists.
$[C]=\left[\begin{array}{ccccc}C_{1}(\theta) & -C_{1}(\theta) & 0 & 0 & 0 \\ -C_{1}(\theta) & C_{1}(\theta)+C_{2} & -C_{2} & 0 & 0 \\ 0 & -C_{2} & C_{2}+C_{3} & -C_{3} & 0 \\ 0 & 0 & C_{3} & C_{3}+C_{4} & -C_{4} \\ 0 & 0 & 0 & -C_{4} & C_{4}\end{array}\right] \ldots$

Where,

$$
\begin{gathered}
C_{1}(\theta)=\left\{\begin{array}{cccc}
C_{1} & \theta_{1}-\theta_{2}>e \\
0 & -e \leq \theta_{1}-\theta_{2} \leq e \ldots \ldots \ldots \ldots . . . . \\
C_{1} & \theta_{1}-\theta_{2}<-e
\end{array}\right. \\
{[K]=\left[\begin{array}{ccccc}
K_{1}(\theta) & -K_{1}(\theta) & 0 & 0 & 0 \\
-K_{1}(\theta) & K_{1}(\theta)+K_{2} & -K_{2} & 0 & 0 \\
0 & -K_{2} & K_{2}+K_{3} & -K_{3} & 0 \\
0 & 0 & K_{3} & K_{3}+K_{4} & -K_{4} \\
0 & 0 & 0 & -K_{4} & K_{4}
\end{array}\right] .}
\end{gathered}
$$

Where,

$$
K_{1}(\theta)=\left\{\begin{array}{cc}
K_{1}-K_{1} \frac{e}{\theta_{1}-\theta_{2}} & \theta_{1}-\theta_{2}>e \\
0 & -e \leq \theta_{1}-\theta_{2} \leq e \ldots \\
K_{1}+K_{1} \frac{e}{\theta_{1}-\theta_{2}} & \theta_{1}-\theta_{2}<-e
\end{array}\right.
$$

\subsection{Dynamic Response of Mill Main Drive System}

2.2.1. Determination of the Main Drive System Parameters

In the main drive system of the plate mill, the inertia of the motor rotor can be obtained from the motor parameter table, and other parameters of components can be calculated. Since the axes of the work roll and backup roll are not on the same straight line, the motion of the backup rolls needs to be equivalent to rotation on the same line as the work rolls in accordance with the energy conservation principle. The regular-shape part inertia can be calculated directly, according to the theoretical formula. The irregularshape parts were built with Solidworks software, as shown in Fig. 4. Inertias of these parts can be read from the mass attributes. The torsional stiffness of each component can also be solved by theoretical calculation. There is a series connection relationship between each shaft section of the main drive system. The calculation formula of the series connection equivalent inertia of the main drive system is Eq. (9), and the equivalent torsional stiffness calculation formula is Eq. (10):

$$
J=J_{1}+J_{2}+\cdots+J_{n}
$$


Where $J_{1}, J_{2}, \ldots, J_{\mathrm{n}}$, are the inertias of each shaft segment respectively.

$$
K=\frac{1}{\frac{1}{K_{1}}+\frac{1}{K_{2}}+\cdots+\frac{1}{K_{1}}}
$$

Where $K_{1}, K_{2}, \ldots, K_{\mathrm{n}}$, are the torsional stiffness of each component respectively.

Calculation results of the rotor inertia of the upper and down main drive systems are shown in Table $\mathbf{2}$, and the torsional stiffnesses of each shaft segment are shown in the Table 3.

\subsubsection{Excitation and Initial Conditions during the Biting Process}

During the biting process, the external load of Eq. (1) is the torque. According to the actual working conditions of plate rolling, the loading mode of the torque is slope type, as shown in Fig. 6. During the biting process within $T_{0}$, the torque at the roll increases linearly: $M(\mathrm{t})=-\frac{M_{0}}{T_{0}} t$, and the torque at the motor: $M(\mathrm{t})=\frac{M_{0}}{T_{0}} t$. After $T_{0}$, the stable torque is $M_{0}$. Then the following relationship is expressed:

The first stage, when $t<T_{0}$ :

$$
\{M(t)\}=\left\{\frac{M_{0}}{T_{0}} t, 0,0,0,-\frac{M_{0}}{T_{0}} t\right\}^{T}
$$

The second stage, when $t \geq T_{0}$ :

Table 2. Inertia of the main drive system.

\begin{tabular}{cccccc}
\hline Items & $\begin{array}{c}J_{1} \\
\left(\mathrm{~kg} \cdot \mathrm{m}^{2}\right)\end{array}$ & $\begin{array}{c}J_{2} \\
\left(\mathrm{~kg} \cdot \mathrm{m}^{2}\right)\end{array}$ & $\begin{array}{c}J_{3} \\
\left(\mathrm{~kg} \cdot \mathrm{m}^{2}\right)\end{array}$ & $\begin{array}{c}J_{4} \\
\left(\mathrm{~kg} \cdot \mathrm{m}^{2}\right)\end{array}$ & $\begin{array}{c}J_{5} \\
\left(\mathrm{~kg} \cdot \mathrm{m}^{2}\right)\end{array}$ \\
\hline upper system & 93910 & 7588 & 3286 & 3962 & 38227 \\
down system & 97426 & 10281 & 3286 & 3962 & 38227 \\
\hline
\end{tabular}

Table 3. Torsional stiffness of main drive system.

\begin{tabular}{ccccc}
\hline Items & $\begin{array}{c}K_{1} \\
(\mathrm{~N} \cdot \mathrm{m} / \mathrm{rad})\end{array}$ & $\begin{array}{c}K_{2} \\
(\mathrm{~N} \cdot \mathrm{m} / \mathrm{rad})\end{array}$ & $\begin{array}{c}K_{3} \\
(\mathrm{~N} \cdot \mathrm{m} / \mathrm{rad})\end{array}$ & $\begin{array}{c}K_{4} \\
(\mathrm{~N} \cdot \mathrm{m} / \mathrm{rad})\end{array}$ \\
\hline upper system & 967237664 & 671942717 & 1107745030 & 492099897 \\
down system & 311827089 & 671942717 & 1107745030 & 492099897 \\
\hline
\end{tabular}

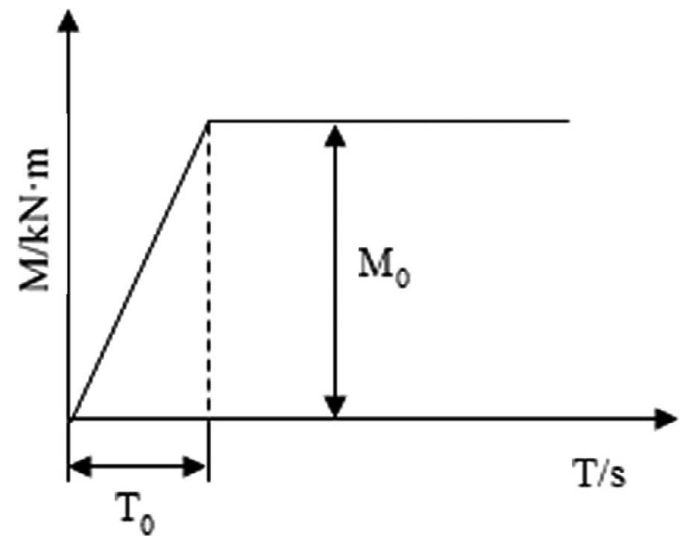

Fig. 6. Slope type loading mode of torque.

$$
\{M(t)\}=\left\{M_{0}, 0,0,0,-M_{0}\right\}^{T}
$$

The excitation $\{M(t)\}$ of the main drive system is used to replace $\left\{M_{F}\right\}$ in Eq. (1), and the torque of each shaft segment in the system can be calculated according to the angular displacement $\theta$.

$$
M_{i}=K_{i}\left(\theta_{i+1}-\theta_{i}\right)
$$

The biting impact on the main drive system of the plate mill can be regarded as a motion superimposed on the original constant velocity rotating motion of the shafting system. When studying the torsional vibration of the biting impact, the original constant velocity motion can be ignored. So, the initial conditions can be assumed to be:

$$
\{\theta\}=0,\{\dot{\theta}\}=0,\{\ddot{\theta}\}=0
$$

\subsubsection{Numerical Solution}

The Runge-Kutta method is used to solve the differential equations of the main drive system, with MATLAB software. The dynamic response of each shaft segment torque is calculated, and the calculation flow chart is shown as Fig. 7:

\subsubsection{Dynamic Response and Peak Torque Calculation Result}

According to the practical situation of the field, the biting time $0.06 \mathrm{~s}$, and the steady-state torque of single motor $4000 \mathrm{kN} \cdot \mathrm{m}$ was used as simulation conditions. First, simulation in an ideal situation without clearance was performed. The dynamic response curves of the upper and down main drive systems are shown in Figs. 8 and 9.

It can be seen from Figs. 8 and 9, that during biting period, the torque rapidly increases to the maximum value, and then gradually decreases to the stable value. It is almost same as the actual situation shown in Fig. 1.

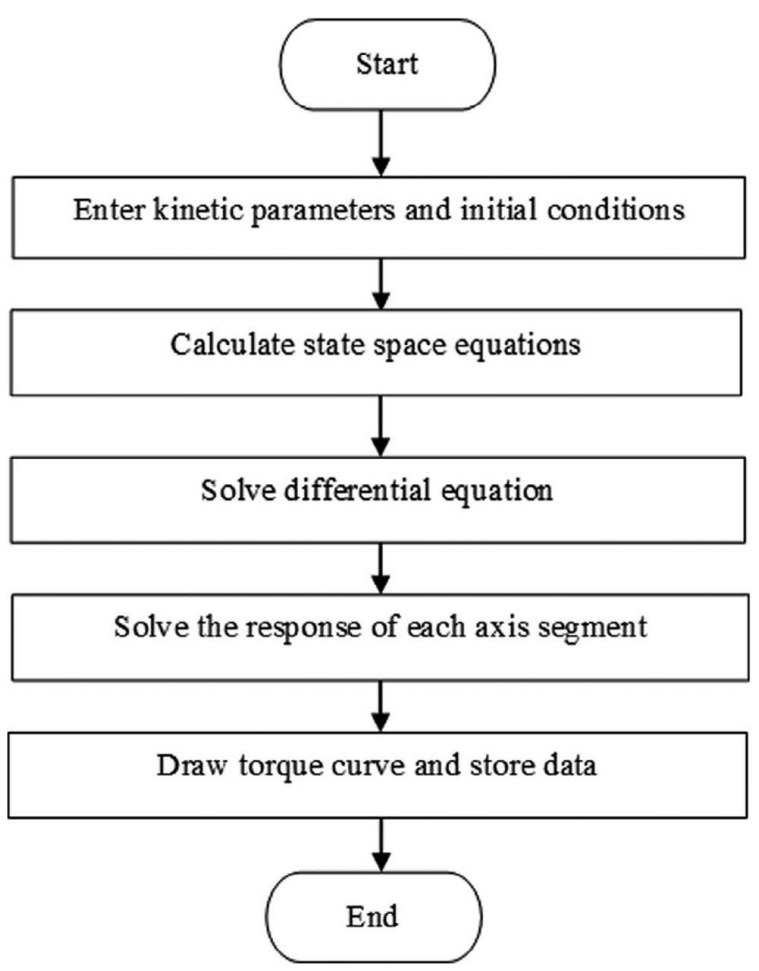

Fig. 7. Torque dynamic response calculation flow chart. 

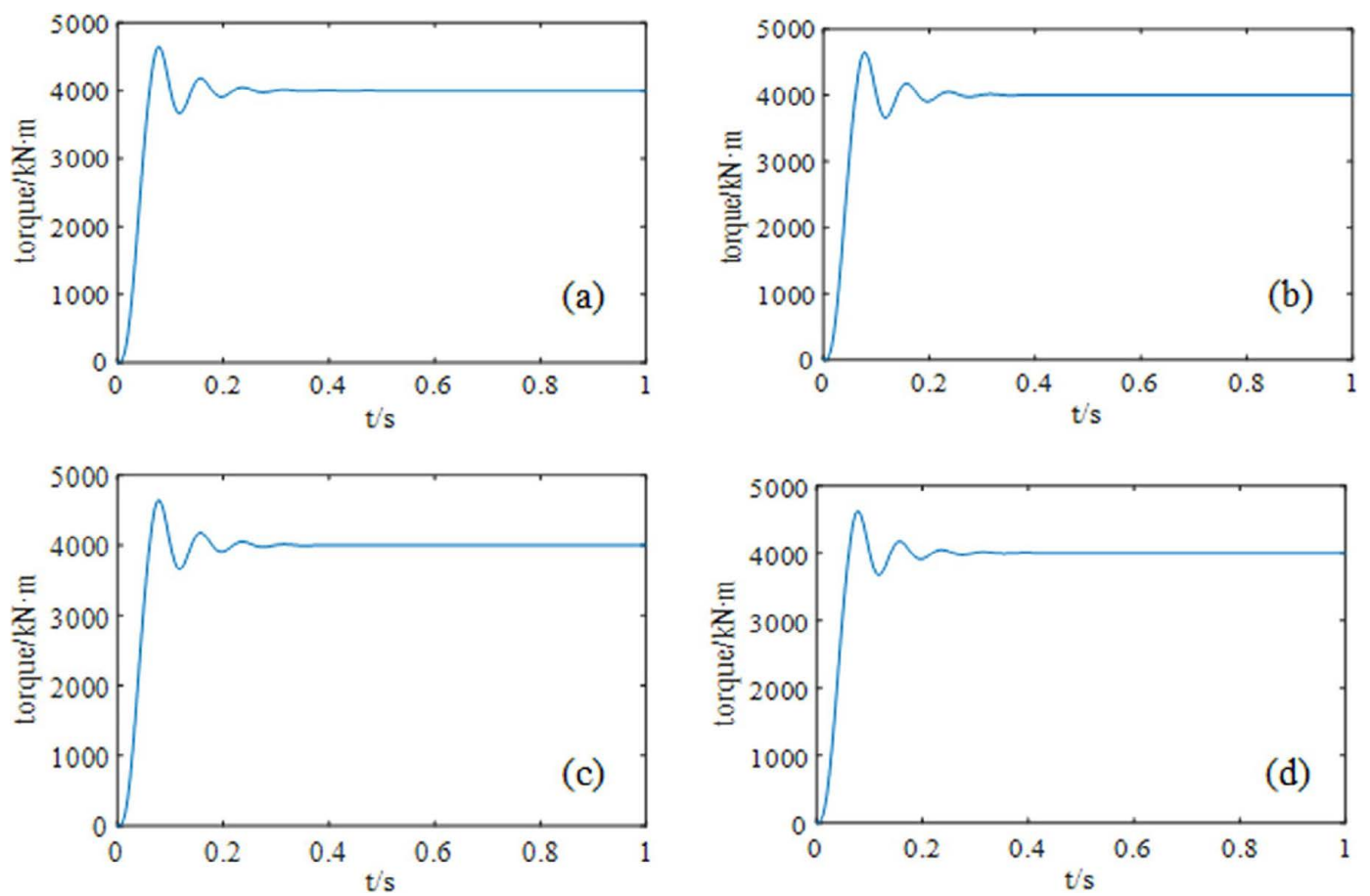

Fig. 8. Tuque-Time curves of the upper drive system: (a) segment 1, (b) segment 2, (c) segment 3, (d) segment 4. (Online version in color.)
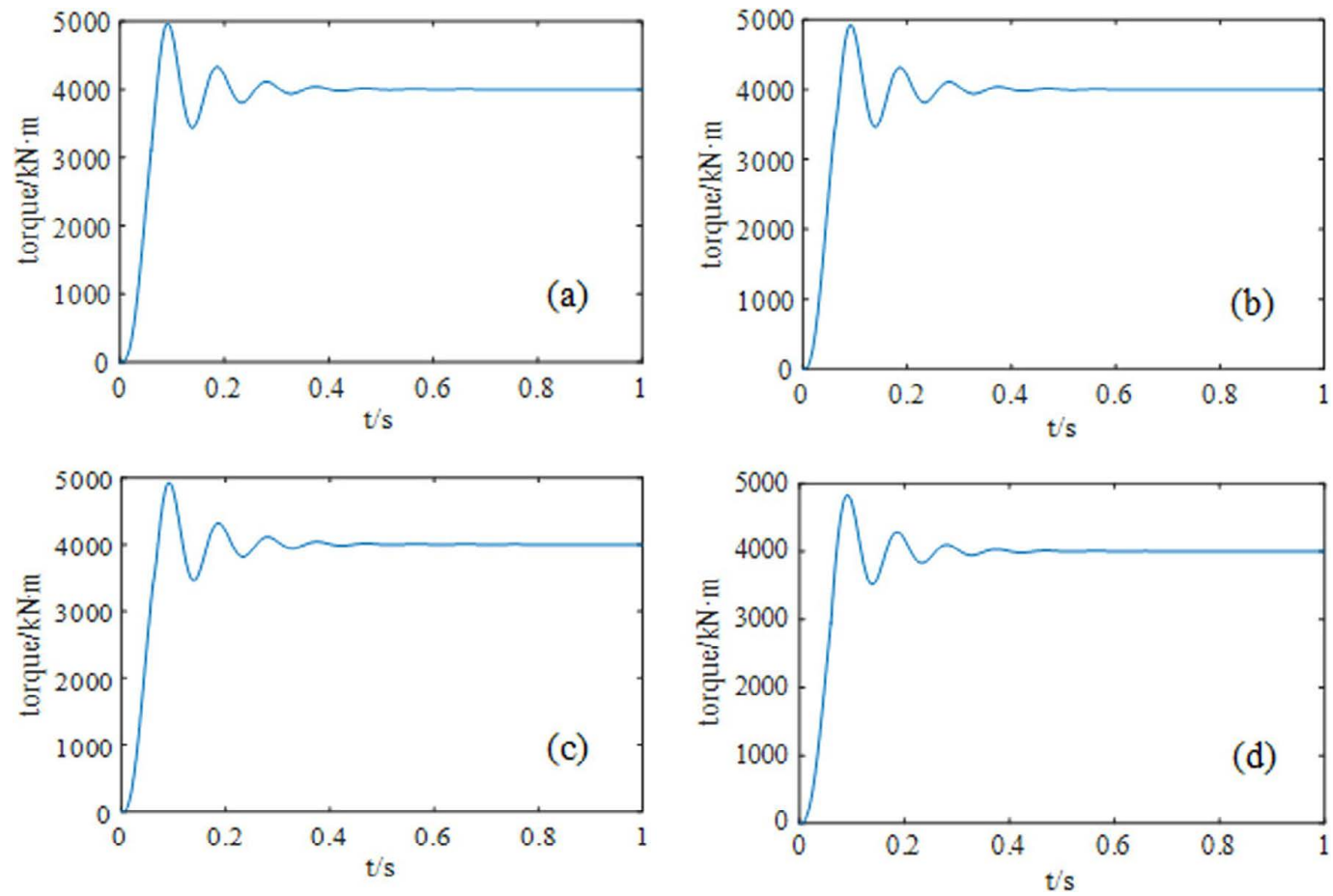

Fig. 9. Torque-Time curves of the down drive system: (a) segment 1, (b) segment 2, (c) segment 3, (d) segment 4 . (Online version in color.)

Torque amplification factor (TAF) refers to the ratio of the maximum torque $M_{\max }$ to the stable torque $M_{0},{ }^{16)}$ shown as Eq. (15). It is an important scale of the torque variation when the main drive system is subject to torsional vibration.

$$
T A F=\frac{M_{\max }}{M_{0}}
$$

TAF values of each segments are shown in Table 4. The average TAF at the segment 1 has the largest value, and the measured torque of the main motor can be used as the actual value of this part. So, the segment 1 is used as the research object, subsequently.

The dynamic responses of the torque under different rolling conditions are calculated, and the peak torque value of the biting impact is extracted and compared with the measured peak torque value of the main motor during rolling process, as shown in Fig. 10. The maximum deviation is within $\pm 8 \%$, and the average error accuracy is within $\pm 5 \%$. 
Table 4. TAF of main drive system.

\begin{tabular}{ccccc}
\hline Items & Segment 1 & Segment 2 & Segment 3 & Segment 4 \\
\hline upper drive system & 1.16 & 1.16 & 1.17 & 1.16 \\
down drive system & 1.28 & 1.27 & 1.26 & 1.25 \\
average & 1.22 & 1.215 & 1.215 & 1.205 \\
\hline
\end{tabular}

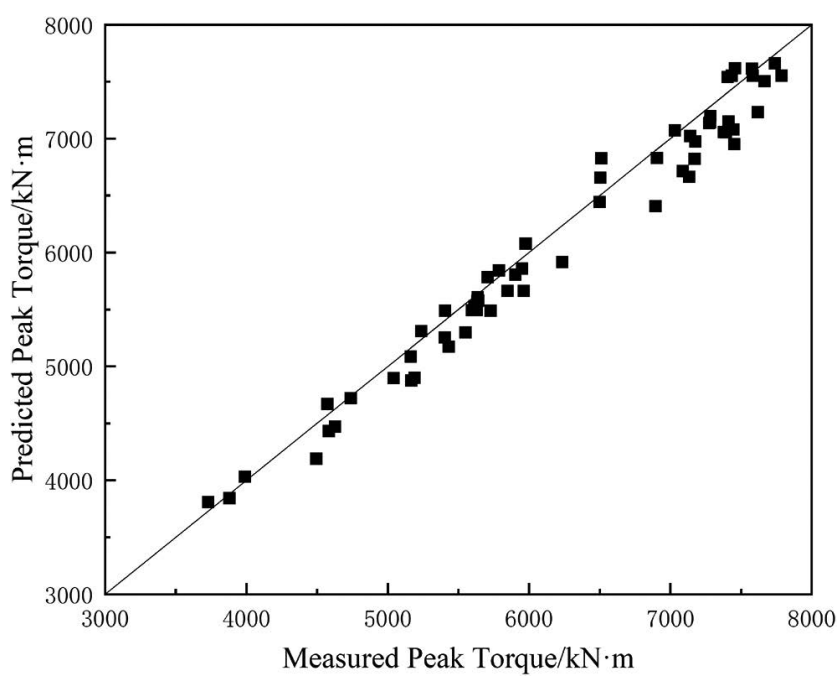

Fig. 10. Biting peak torque calculation error analysis.

\section{Analysis of Influence Factors to Biting Peak Torque}

In the plate rolling process, biting time and steady-state torque are the most important factors affecting the biting peak torque. Therefore, in this section, the effects of different biting time and steady-state torque on the biting peak torque are studied. The simulation range of biting time is $0.05 \mathrm{~s}-0.09 \mathrm{~s}$, and range of steady-state torque of single motor is $2000-4000 \mathrm{kN} \cdot \mathrm{m}$.

\subsection{Effect of Biting Time on Biting Peak Torque}

The biting time is the time needed for the rolling stock to be completely bitten into the roll. In the plate rolling process, it is the time from the head contact the roll to the filling of the entire deformation zone, as shown in Eq. (16):

$$
T_{0}=\frac{\text { Bite angle }(\varphi)}{\text { Roll biting } \operatorname{speed}(\omega)}
$$

According to the bite angle formula, it is concluded that biting time is related to the roll speed, reduction, and roll diameter, as shown in Eq. (17).

$$
T_{0}=\frac{30}{n \pi} \times \arccos \left(1-\frac{\Delta h}{D}\right)
$$

where: $n$ is roll speed, rpm; $\Delta h$ is reduction, $\mathrm{mm}$ and $\mathrm{D}$ is roll diameter, $\mathrm{mm}$.

Analyze the relationship between the biting time and the peak torque under different steady-state torque of single motor $(2000 \mathrm{kN} \cdot \mathrm{m}, 2500 \mathrm{kN} \cdot \mathrm{m}, 3000 \mathrm{kN} \cdot \mathrm{m}, 3500 \mathrm{kN} \cdot \mathrm{m}$, $4000 \mathrm{kN} \cdot \mathrm{m})$. As shown in Fig. 11, the biting peak torque is the total value of upper and down main drive system, and it decreases with the biting time increasing. The deceasing rate is almost same for different steady-state torque. So, in the field, the biting peak torque can be decreased by increas-

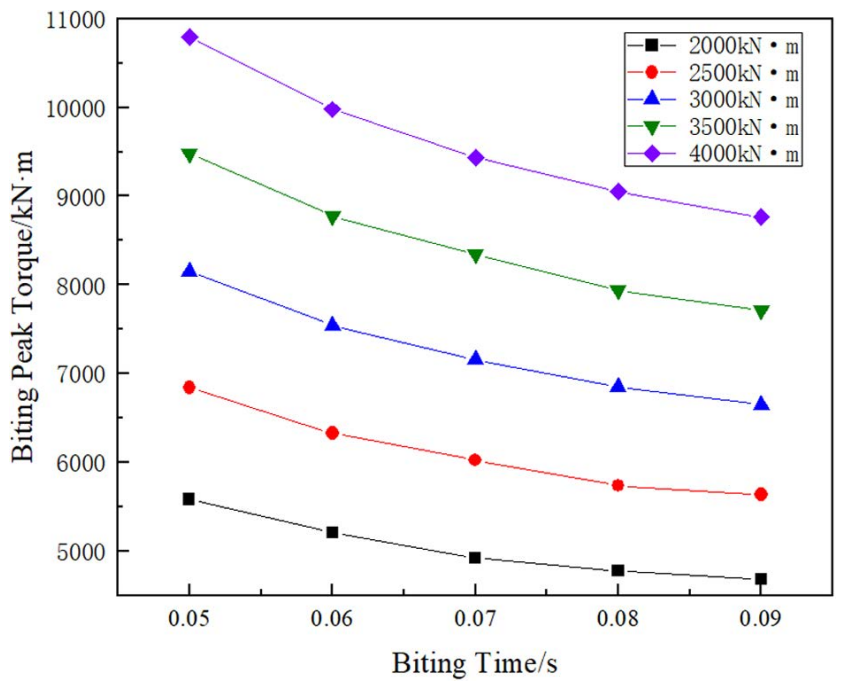

Fig. 11. Effect of biting time on biting peak torque. (Online version in color.)

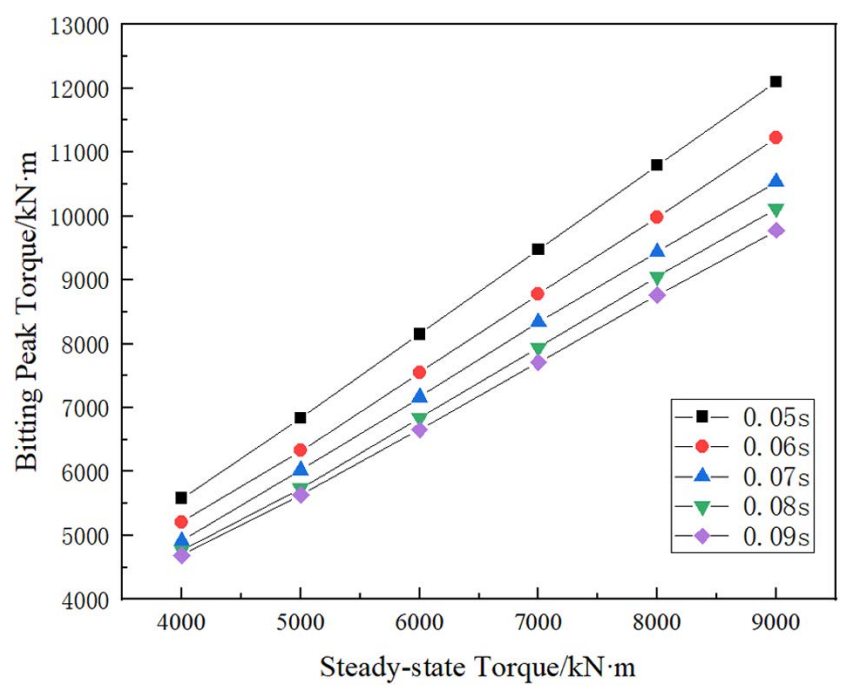

Fig. 12. Effect of steady-state torque on biting peak torque (Online version in color.)

ing the biting time, in order to reduce the biting impact phenomenon.

\subsection{Effect of Steady-State Torque on Biting Peak Torque}

The relationship between the steady-state torque and the biting peak torque under different biting time $(0.05 \mathrm{~s}, 0.06$ s, $0.07 \mathrm{~s}, 0.08 \mathrm{~s}, 0.09 \mathrm{~s})$ was also analyzed. The relationship between total biting peak torque and total steady-state torque is shown in Fig. 12. It can be seen that the biting peak torque increases with the steady-state torque increasing, and the increasing rate is almost linear. The increasing rate is decreased with the biting time increasing.

\section{Torque Model with Biting Impact Considered}

\subsection{Steady-state Rolling Torque Model}

The steady-state rolling torque needs to be calculated according to the steady-state rolling process conditions, and it affects the biting impact torques directly. Nowadays, multiplication of rolling force and force arm is generally 
used as the torque calculation equation form in production. The force arm can be calculated by multiplying contact arc length and level arm ratio. ${ }^{10)}$ It is shown as Eq. (18) and Fig. 13. This method has the advantages of simple model form and clear physical meaning.

$$
M_{0}=2 \cdot F \cdot \chi \cdot l
$$

Where: $M_{0}$ is steady-state rolling torque, $F$ is rolling force, $\chi$ is lever arm ratio, and $l$ is contact arc length.

If the calculation accuracy of the force is considered to be sufficiently high in this model, the level arm ratio will affect the calculation accuracy of the steady-state torque directly. The arithmetic average aspect ratio (ratio of contract length to mean thickness in roll gap) and reduction rate are the main influences of the level arm ratio model. ${ }^{8,12)}$ Based on the actual field data, the actual level arm ratio can be got and the level arm ratio mathematical model is rebuilt through multiple nonlinear regression analysis, shown as Eq. (19).

$$
\begin{array}{r}
\chi=a_{1}+a_{2} \cdot \frac{h_{c}}{l}+a_{3} \cdot\left(\frac{h_{c}}{l}\right)^{2}+a_{4} \cdot\left(\frac{h_{c}}{l}\right)^{3}+a_{5} \cdot \sqrt{1-\varepsilon} \ldots \\
h_{c}=(H+h) / 2 \ldots \ldots \ldots \ldots \ldots \ldots \ldots \ldots \ldots \ldots \ldots \ldots \ldots \ldots \ldots \ldots \ldots \ldots \ldots \ldots \ldots \ldots \ldots \ldots
\end{array}
$$

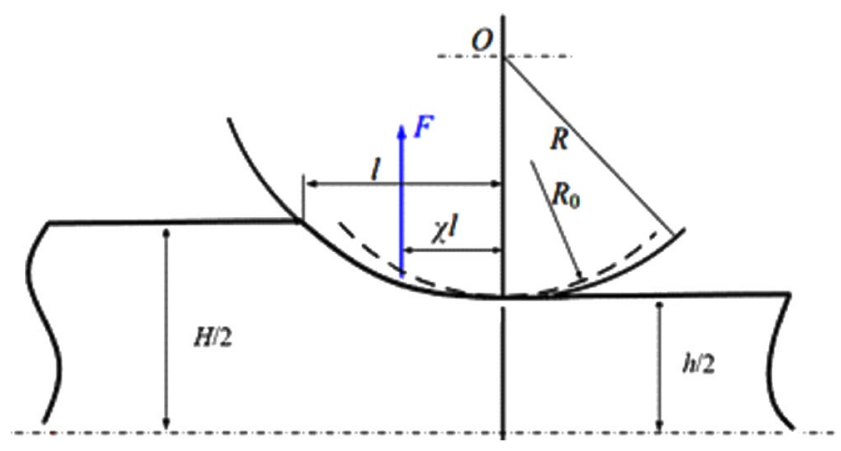

Fig. 13. Diagram of roll zone in plate rolling process. (Online version in color.)

Table 5. Partial actual data for level arm ratio model regression.

\begin{tabular}{ccc}
\hline Reduction & Aspect ratio & Level arm ratio \\
\hline 0.238 & 0.87 & 0.5225 \\
0.224 & 0.86 & 0.541 \\
0.185 & 0.41 & 0.632 \\
0.222 & 0.85 & 0.5355 \\
0.228 & 0.46 & 0.5965 \\
0.19 & 0.33 & 0.639 \\
0.207 & 0.36 & 0.626 \\
0.16 & 0.546 & 0.6275 \\
0.24 & 0.57 & 0.565 \\
0.242 & 0.77 & 0.523 \\
$\ldots$ & $\ldots$ & $\ldots$ \\
\hline
\end{tabular}

$$
\varepsilon=\frac{H-h}{H}
$$

Where, $a_{1}-a_{5}$ are the regression coefficients; $\frac{h_{c}}{l}$ is the aspect ratio; $H, h, h_{c}$ is pass entry thickness, exit thickness, and average thickness respectively. $l$ is contact length, $R$ is flattening roll radius, and $\varepsilon$ is reduction rate.

The coefficients $a_{1}-a_{5}$ are regressed as $-0.625,0.064$, $-0.446,0.228$ and 1.446 respectively. Partial actual data are shown in Table 5. The predicted and measured torques are compared as shown in Fig. 14. The maximum error of the torque model is within $\pm 12.3 \%$, and the average error is $\pm 8.27 \%$.

\subsection{Peak Biting Torque Model}

The peak biting torque is related to the steady-state torque and biting time. According to the actual production

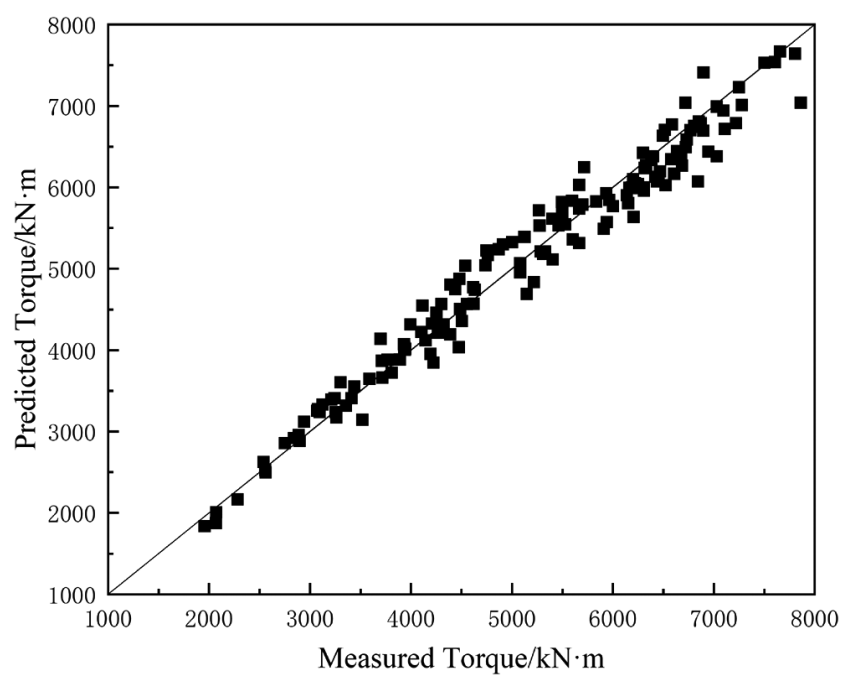

Fig. 14. Comparison between predicted and measured steadystate torque.

Table 6. Partial data for Peak biting torque model regression.

\begin{tabular}{ccccc}
\hline $\begin{array}{c}\text { Biting } \\
\text { time/s }\end{array}$ & $\begin{array}{c}\text { One roll } \\
\text { steady torque/ } \\
\mathrm{kN} \cdot \mathrm{m}\end{array}$ & $\begin{array}{c}\text { Upper roll } \\
\text { peak torque/ } \\
\mathrm{kN} \cdot \mathrm{m}\end{array}$ & $\begin{array}{c}\text { Down roll } \\
\text { peak torque/ } \\
\mathrm{kN} \cdot \mathrm{m}\end{array}$ & $\begin{array}{c}\text { Total peak } \\
\text { torque/ } \\
\mathrm{kN} \cdot \mathrm{m}\end{array}$ \\
\hline 0.05 & 2500 & 3250 & 3595 & 6845 \\
0.05 & 2600 & 3369 & 3733 & 7102 \\
0.05 & 2700 & 3496 & 3882 & 7378 \\
0.06 & 2800 & 3320 & 3752 & 7072 \\
0.06 & 2900 & 3439 & 3857 & 7296 \\
0.06 & 3000 & 3558 & 3987 & 7545 \\
0.07 & 3100 & 3450 & 3918 & 7368 \\
0.07 & 3200 & 3564 & 4041 & 7605 \\
0.07 & 3300 & 3679 & 4181 & 7860 \\
0.08 & 3400 & 3706 & 4018 & 7724 \\
0.08 & 3500 & 3818 & 4129 & 7947 \\
0.08 & 3600 & 3965 & 4235 & 8200 \\
$\ldots$ & $\ldots$ & $\ldots$ & $\ldots$ & $\ldots$ \\
\hline
\end{tabular}




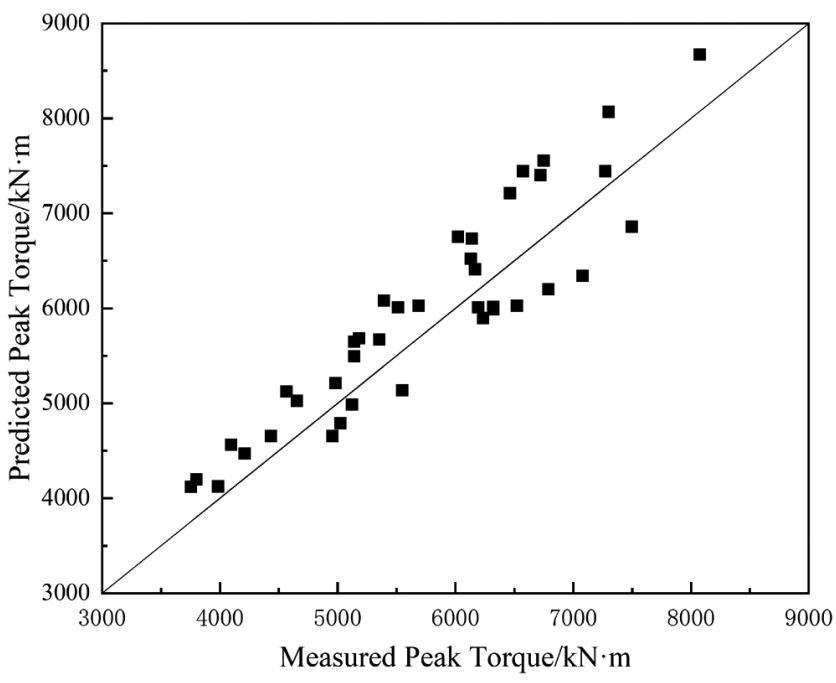

Fig. 15. Comparison between predicted and measured peak biting impact torque.

conditions on the site, it can be known that the steady-state torque of single motor is mainly concentrated in the range of $2000-4000 \mathrm{kN} \cdot \mathrm{m}$, and the biting time range is $0.05-0.09$ $\mathrm{s}$. The peak biting torque under different parameters were simulated, and based on the simulation data, a multivariate regression prediction model of the peak biting torque is established as Eq. (23), and partial data are shown in Table 6.

$M_{\max }=2.54 \cdot M_{0}-413459 \cdot t+2302031 \cdot t^{2}+17387 \ldots$

where: $M_{\max }$ and $M_{0}$ are peak torque and steady-state torque respectively, $\mathrm{N} \cdot \mathrm{m}$; and $t$ is biting time, s.

With the regression model, the predicated and measured peak biting torques are compared as shown in Fig. 15, that the maximum error predicted by the model is within $\pm 12 \%$ The average error is within $\pm 10 \%$.

\section{Conclusion}

The five-degree-of-freedom mechanical dynamics model was established for the main drive system of the actual heavy plate mill, based on mechanical dynamics. The clearance effect was considered in this model, and the influence of biting time and steady-state torque on the biting peak torque was analyzed. The biting peak torque decreases with the biting time increasing, and increases with the steadystate torque increasing.

The steady-state torque model was improved by rebuilding level arm ratio model, based on the traditional model form. The influence of deformation area arithmetic average aspect ratio and reduction rate were considered. The calculation model of biting peak torque is regressed with simulation data, considering biting time and steady-state torque influence.

Accuracy of the steady-state torque model and the biting peak torque model was verified. The average deviation of steady-state torque and biting peak torque are within $\pm 8 \%$, and $\pm 10 \%$ respectively. The accuracy of these models can be improved by offline intelligent method and online learning function, subsequently.

\section{Acknowledgments}

This work was financially supported by the Fundamental Research Funds for the Central Universities (No.: N160704003; N170708020).

\section{REFERENCES}

1) E. Orowan: Proc. Inst. Mech. Eng., 150 (1943), 140.

2) R. B. Sims: Proc. Inst. Mech. Eng., 168 (1954), 191.

3) H. Ford and J. M. Alexander: J. Inst. Met., 92 (1964), 397.

4) J. W. Green and J. F. Wallace: J. Mech. Eng. Sci., 4 (1962), 136.

5) I. J. Freshwater: Int. J. Mech. Sci., 38 (1996), 633.

6) S. X. Chen, W. G. Li and X. H. Liu: Int. J. Mech. Sci., 89 (2014), 256. https://doi.org/10.1016/j.ijmecsci.2014.09.011

7) S. H. Zhang, D. W. Zhao and C. R. Gao: Int. J. Mech. Sci., 57 (2012), 74. https://doi.org/10.1016/j.ijmecsci.2012.02.006

8) C. H. Moon and Y. Lee: ISIJ Int., 48 (2008), 1409

9) O. A. Gasiyarova, S. S. Voronin, E. A. Maklakova and V. R. Gasiyarov: Procedia Eng., 150 (2016), 1415. https://doi.org/10.1016/j. proeng.2016.07.205

10) J. Sun, Y. M. Liu, Q. L. Wang, Y. K. Hu and D. H. Zhang: Int. J. Adv. Manuf. Technol., 97 (2018), 1847. https://doi.org/10.1007/ s00170-018-2078-7

11) Z. H. Wang, D. H. Zhang, D. Y. Gong and W. Peng: ISIJ Int., 59 (2019), 1604. https://doi.org/10.2355/isijinternational.ISIJINT-2018-846

12) Y. Y. Yang, D. A. Linkens, J. Talamantes-Silva and I. C. Howard: ISIJ Int., 43 (2003), 1957.

13) M. Bagheripoor and H. Bisadi: Appl. Math. Model., 37 (2013), 4593. https://doi.org/10.1016/j.apm.2012.09.070

14) P. Montmitonnet and P. Buessler: ISIJ Int., 31 (1991), 525

15) M. Ataka: ISIJ Int., 55 (2015), 89. https://doi.org/10.2355/ isijinternational.55.89

16) H. Jewik, R. P. Stratford and C. W. Thomas: IEEE Trans. Ind. Gen. Appl., IGA-5 (1969), 333.

17) W. Dobrucki and A. Świạtoniowski: J. Mater. Process. Technol., 61 (1996), 323.

18) Z. H. Wang and D. J. Wang: J. Mater. Process. Technol., 97 (2000), 69.

19) G. J. Du, Z. J. Zhang and C. Y. Gao: Iron Steel, 48 (2013), No. 2, 39 (in Chinese). https://doi.org/10.13228/j.boyuan.issn0449749x.2013.02.003

20) C. Y. Gao, G. J. Du and Z. J. Zhang: J. Mech. Eng., 50 (2014), 130 (in Chinese). https://doi.org/10.3901/JME.2014.03.130

21) P. M. Shi, K. W. Xia, B. Liu and D. X. Hou: J. Vib. Shock, 34 (2015), 35 (in Chinese). https://doi.org/10.13465/j.cnki.jvs.2015.12.007

22) Y. Q. Wang, N. Qin, Z. F. Liu, X. C. Yan, Y. X. Luo and G. Lei: $J$. Vib. Shock, 36 (2017), 164 (in Chinese). https://doi.org/10.13465/j. cnki.jvs.2017.18.024

23) I. A. Yakimov, S. S. Voronin, E. A. Maklakova and A. S. Maklakov: Procedia Eng., 206 (2017), 1839.

24) H. Naitoh and K. Suzuki: PESC Record. 27th Annual IEEE Power Electronics Specialists Conf., IEEE, Piscataway, NJ, (1996), 925.

25) P. Belli, S. Bittanti and A. De Marco: J. Dyn. Syst. Meas. Control, 126 (2004), 811.

26) P. V. Krot: 18th IEEE Int. Conf. on Control Applications, IEEE, Piscataway, NJ, (2009), 1368. 